\title{
Microstructure and magnetic properties of grain boundary modified recycled Nd-Fe-B sintered magnets
}

\author{
H. Sepehri-Amin ${ }^{1}$, T. Ohkubo ${ }^{1}$, M. Zaktonik ${ }^{2}$, D. Prosperi², \\ P. Afiuny ${ }^{2}$, C. O. Tudor ${ }^{2}$, and K. Hono ${ }^{1}$ \\ ${ }^{1}$ Elements Strategy Initiative Center for Magnetic Materials, National Institute for Materials \\ Science, 1-2-1 Sengen, Tsukuba 305-0047, Japan \\ ${ }^{2}$ Urban Mining Technology Co., Wilmington, DE 21903, USA.
}

Full-density recycled Nd-Fe-B sintered magnets were produced from collected waste NdFe-B magnets with the coercivity, $\mu_{0} H_{\mathrm{c}}$, of $1.30 \mathrm{~T}$ and remanence, $\mu_{0} M_{\mathrm{r}}$, of $1.37 \mathrm{~T}$. A small fraction of $\mathrm{Nd}_{6} \mathrm{Dy}_{21} \mathrm{Co}_{19} \mathrm{Cu}_{2.5} \mathrm{Fe}$ powder (Grain Boundary Modified (GBM ${ }^{\mathrm{TM}}$ ) powder) was blended to the powders obtained from the Nd-Fe-B waste magnets. The addition of $5.0 \mathrm{wt} \%$ $\mathrm{GBM}^{\mathrm{TM}}$ powder resulted in $\mu_{0} H_{c}=2.36 \mathrm{~T}$ with $\mu_{0} M_{r}=1.29 \mathrm{~T}$ in recycled magnets. The temperature coefficient of intrinsic coercivity, $\beta$, in the recycled magnet was measured to be $0.47 \% /{ }^{\circ} \mathrm{C}$. Microstructure studies showed that the addition of the $\mathrm{GBM}^{\mathrm{TM}}$ powder increases the volume fraction of a metallic Nd-rich phase in the recycled magnets. 3D tomography revealed a good interconnection of Nd-rich phases through the grain boundaries of the recycled magnet. Microstructure studies suggested that obtained high coercivity in the recycled magnet with 5.0 $\mathrm{wt} \%$ addition of GBM${ }^{\mathrm{TM}}$ is due to the formation of distinct grain boundary phase combined with the formation of Dy-rich shell in the $\mathrm{Nd}_{2} \mathrm{Fe}_{14} \mathrm{~B}$ grains with $\sim 0.8$ at. \% Dy.

Keywords: Nd-Fe-B sintered magnets, Recycling, Coercivity, Grain boundary, Microstructure. 


\section{Introduction}

Anisotropic Nd-Fe-B sintered magnets are widely used in a variety of applications such as electric power generation and transportation. The typical composition of the anisotropic Nd-Fe-B sintered magnets used in the traction motors of hybrid cars is around $\mathrm{Nd}_{22} \mathrm{Dy}_{11} \mathrm{Fe}_{65} \mathrm{~B}_{1} \mathrm{Cu}_{0.1} \mathrm{wt} \%$ indicating that $33 \mathrm{wt} \%$ of these sintered magnets is comprised of precious rare earth elements [1]. Although the production and the applications of Nd-Fe-B permanent magnets are increasing year by year, the life-time of various appliances in which $\mathrm{Nd}-\mathrm{Fe}-\mathrm{B}$ based permanent magnets are used is limited [2]. Hence, it is important to recycle the Nd-Fe-B magnets after reaching to the end of the life of the devices containing Nd-Fe-B based permanent magnets.

Several methods to recycle waste $\mathrm{Nd}-\mathrm{Fe}-\mathrm{B}$ sintered magnets have been reported. Itoh et al. produced isotropic Nd-Fe-B bonded magnets by melt-spinning Nd-Fe-B waste sintered magnets [3]. Hydrogen decrepitation was introduced as a method to make powders out of Nd-FeB waste sintered magnets [4-6]. The hydrogenation decomposition desorption recombination (HDDR) process was also employed to produce powders for bonded magnets applications from Nd-Fe-B waste sintered magnets [4-6]. The recycled powders can be also used to make anisotropic Nd-Fe-B sintered magnets [7-9]. However, the low coercivity of the recycled powders is one of the drawbacks to develop high coercivity anisotropic sintered magnets. In addition, full density Nd-Fe-B sintered magnets cannot be produced only from the recycled NdFe-B powders because of the oxidation of Nd-rich phases during the recycling process. Jang et al. and Kwon et al. proposed a method to produce high coercivity recycled powders using $\mathrm{DyF}_{3}$ salt to form $(\mathrm{Nd}, \mathrm{Dy})_{2} \mathrm{Fe}_{14} \mathrm{~B}$ shell on the surface of the powders $[10,11]$. On the other hand, Kawasaki et al. successfully produced the full density anisotropic Nd-Fe-B sintered magnets that have comparable magnetic properties to those of initial magnets by adding $\mathrm{Nd}_{80} \mathrm{Fe}_{20}$ binary powder to jet milled $\mathrm{Nd}-\mathrm{Fe}-\mathrm{B}$ recycled powders [7]. Zaktonik et al. also reported that the 
addition of 1.0 at. $\% \mathrm{Nd}$ to the recycled jet-milled $\mathrm{Nd}-\mathrm{Fe}-\mathrm{B}$ powders is sufficient to recover the magnetic properties of recycled magnets [9]. More recently, Li et al. reported recycled Nd-Fe-B sintered magnets with a comparable remanent magnetization, coercivity and maximum energy product by blending $\mathrm{Nd}_{22} \mathrm{PrFe}_{14} \mathrm{~B}$ powder with the recycle powders before sintering [12]. These reports indicate that the composition selection of the powders to be added to the recycled powders is crucial to recover the initial hard magnetic properties. In this work, we report a new composition of additive powders to be used in two powder blending method to modify the grain boundary composition of the recycled full-density Nd-Fe-B sintered magnets. The recycled anisotropic Nd-Fe-B sintered magnet showed superior coercivity compared to those of the initial Nd-Fe-B waste magnets. The microstructure of the magnets was studied in detail to correlate the magnetic properties with the microstructures of the recycled Nd-Fe-B sintered magnet.

\section{Experimental procedure}

Inputs of $100 \mathrm{~kg}$ batches of waste magnets collected from a range of end-of-life applications such as hard disk drives, magnetic resonance imaging machines and loudspeakers were recycled via Magnet-to-Magnet Recycling Process [13]. These magnets are generally covered with a corrosion resistive coating such as $\mathrm{Ni}, \mathrm{Zn}$, and Al. These coatings were mechanically removed using a blasting apparatus (model 28GL) at a rate of $680 \mathrm{~kg} / \mathrm{min}$ steel shot before further processing. Aiming at improving coercivity, and thermal stability overall, the optimum $\mathrm{Nd}_{6} \mathrm{Dy}_{21} \mathrm{Co}_{19} \mathrm{Cu}_{2.5} \mathrm{Fe}$ composition blend of transitional metal and lanthanides was chosen so to allow the GBE ${ }^{\mathrm{TM}}$ (Grain Boundary Engineering) of the main phase. The $\mathrm{Nd}_{6} \mathrm{Dy}_{21} \mathrm{Co}_{19} \mathrm{Cu}_{2.5} \mathrm{Fe}$ alloy powder was therefore blended to recycled powder to form a modified grain boundary phase; hereafter, this powder is called grain boundary modified $\left(\mathrm{GBM}^{\mathrm{TM}}\right)$ 
powder. $5.0 \mathrm{wt} \% \mathrm{GBM}^{\mathrm{TM}}$ powder was added to waste magnet powders to produce new recycled sintered magnets suitable for high temperature applications.

Starting waste material with the composition of $\mathrm{Nd}_{21.07} \mathrm{Pr}_{7.14} \mathrm{Dy}_{0.4} \mathrm{Fe}_{69.1} \mathrm{Ga}_{0.11} \mathrm{Zr}_{0.12} \mathrm{Al}_{0.25} \mathrm{Co}_{0.55} \mathrm{Cu}_{0.16} \mathrm{~B}_{0.96} \mathrm{C}_{0.07} \mathrm{O}_{0.07}$ wt $\%$ was used to produce recycled magnets. The waste magnets blended with the $\mathrm{GBM}^{\mathrm{TM}}$ powder were first coarsely milled and homogenized using a hydrogen-mixing reactor. This reactor was first evacuated and heated to $80^{\circ} \mathrm{C}$ before admitting hydrogen at a pressure of 0.9 bar. This stage is completed when the pressure gauge becomes stable, indicating that no more hydrogen is being adsorbed. The material was then transferred to a jet milling machine (model: XDK QLMR 350) to achieve a narrow powder size distribution of $3.5 \mu \mathrm{m}$, which was then sieved to remove large oxide particles. Powders were then compacted under a magnetic field to form anisotropic green compacts. The green body was then transferred to a hydraulic chamber and subjected to an isostatic pressure of $100 \mathrm{MPa}$. The aligned and isostatically pressed green compacts were transferred to a graphite tray under an inert atmosphere and then to a vacuum sintering and annealing furnace. The densities of the recycled Nd-Fe-B sintered magnets were determined by a density balance under a temperature controlled ionized water. Cylindrical magnets $(10 \mathrm{~mm}$ in diameter and $10 \mathrm{~mm}$ in height) were cut from a recycled Nd-Fe-B sintered block using a wirecutting machine, and the magnetic properties were then measured using a close looped permeameter after pulse magnetizing in a magnetic field of $4 \mathrm{~T}$. Chemical composition is analyzed using inductive coupled plasma (ICP) before, during, and after the recycling process. Scanning electron microscopy (SEM) backscattered electron (BSE) and in-lens secondary electron (IL-SE) observations were carried out using a Carl Zeiss Cross-Beam 1540EsB. Transmission electron microscopy (TEM) was performed using a Titan G2 80-200 TEM with a 
probe aberration corrector. Energy dispersive X-ray spectroscopy (EDS) was collected using a FEI Super-X EDX detector.

\section{Results}

\subsection{Magnetic properties}

Figure 1 (a) shows demagnetization curves of the waste magnet and the recycled magnet. The waste magnet shows $\mu_{0} M_{\mathrm{r}}=1.38 \mathrm{~T}$ and $\mu_{0} H_{\mathrm{c}}=1.3 \mathrm{~T}$. The addition of $5.0 \mathrm{wt}^{0} \mathrm{GBM}^{\mathrm{TM}}$ powder during the recycling process led to the density of $7.55 \mathrm{~g} / \mathrm{cc}$ with $\mu_{0} M_{\mathrm{r}}=1.29 \mathrm{~T}$ and $\mu_{0} H_{\mathrm{c}}=2.36 \mathrm{~T}$. The composition of the recycled magnet with $5.0 \mathrm{wt} \%$ additive was $\mathrm{Nd}_{21.63} \operatorname{Pr}_{6.43} \mathrm{Dy}_{3.42} \mathrm{Fe}_{64.75} \mathrm{Ga}_{0.1} \mathrm{Zr}_{0.11} \mathrm{Al}_{0.28} \mathrm{Co}_{1.74} \mathrm{Cu}_{0.32} \mathrm{~B}_{0.97} \mathrm{C}_{0.12} \mathrm{O}_{0.13}$ wt $\%$. Figure 1 (b) shows coercivity versus temperature for the waste magnet and the recycled magnets. Temperature coefficient of coercivity $(\beta)$ of the waste magnet and recycled magnet measured from $25^{\circ} \mathrm{C}$ to $200{ }^{\circ} \mathrm{C}$ were $-0.50 \% /{ }^{\circ} \mathrm{C}$ and $-0.47 \% /{ }^{\circ} \mathrm{C}$, respectively. The temperature coefficient of remanence $(\alpha)$ measured with the same temperature range were $-0.14 \% /{ }^{\circ} \mathrm{C}$ and $-0.11 \% /{ }^{\circ} \mathrm{C}$ for the waste magnet and recycled magnets, respectively. Note that a more remarkable difference in the temperature coefficients of coercivity and remanence was found between the waste and recycled magnets in favor of the recycled magnets when heating up the specimens from $25{ }^{\circ} \mathrm{C}$ to $80{ }^{\circ} \mathrm{C}$, i.e. $\alpha$ is equal to $-0.12 \% /{ }^{\circ} \mathrm{C}$ and $-0.02 \% /{ }^{\circ} \mathrm{C}$, and $\beta$ is equal to $-0.81 \% /{ }^{\circ} \mathrm{C}$ and $-0.61 \% /{ }^{\circ} \mathrm{C}$ for the waste and the recycled magnets, respectively.

\subsection{Overall microstructure}

Figure 2 (a) and (b) show back scattered electron (BSE) SEM images of the waste magnet and recycled magnet, respectively. In-lens secondary electron (IL-SE) SEM images obtained from the same area are shown in Fig. 2 (c) and (d). In the IL-SE images, Nd-rich oxides 
can be seen with a dark contrast, and metallic Nd-rich phases are observed with a bright contrast [14]. Note that some voids are observed in the microstructure of the waste magnet as pointed out with yellow arrows in Fig. 2 (a) and (c). In addition, cracks are also observed at some grain boundary region of the waste magnet as marked in Fig. 2 (a). The areal fraction of the metallic $\mathrm{Nd}$ and neodymium oxides were calculated for the waste magnet and the recycled magnet based on the contrast of IL-SE images. The areal fraction of metallic neodymium and neodymium oxides in the waste magnet were estimated to be 2.0 and $3.2 \%$, respectively. In the case of the recycled magnet, the areal fraction of neodymium oxides slightly increases to $4.4 \%$ while that of the metallic $\mathrm{Nd}$ phases were estimated to be around $6.1 \%$. This indicates that the addition of the $\mathrm{GBM}^{\mathrm{TM}}$ during powder processing mainly increases the areal fraction of metallic $\mathrm{Nd}$ that is required to form uniform grain boundary phase [15].

Figure 3 (a) and (b) shows higher magnification BSE-SEM images and SEM-EDS maps of $\mathrm{Nd}, \mathrm{Co}, \mathrm{Cu}, \mathrm{O}, \mathrm{Dy}$, and $\mathrm{Zr}$ obtained from the waste magnet and the recycled magnet. In the microstructure of the waste magnet, rare earth $(\mathrm{RE}: \mathrm{Nd}+\mathrm{Dy})$ oxides, one with more enrichment of oxygen and the other with less oxygen can be observed. $\mathrm{Nd}-\mathrm{Cu}$ rich phase can be seen in the microstructure particularly at the triple junction regions as reported in commercial sintered magnets [16]. Zr-rich phase is found in the Nd-rich phases of the waste magnet. In the case of the recycled magnet, RE-oxides and Zr-rich phase can be seen in some of the Nd-rich grains. The distribution of $\mathrm{Cu}$ and $\mathrm{Co}$ suggests that beside $\mathrm{Nd}-\mathrm{Cu}$ rich triple junction phase, $\mathrm{Nd}-\mathrm{Co}-\mathrm{Cu}$ rich phase exist in the microstructure of the recycled magnet. Metallic Nd with small concentration of $\mathrm{Cu}$ is also observed in some of the Nd-rich phases in the recycled magnet.

The Nd-rich phases in the recycled magnet was studied more in detail using TEM. Figure 4 (a) shows STEM-EDS maps of $\mathrm{Nd}, \mathrm{Fe}, \mathrm{Cu}, \mathrm{Zr}, \mathrm{Dy}, \mathrm{Co}$, and $\mathrm{O}$ obtained from the recycled 
magnet. In this STEM-EDS map, 6 different Nd-rich grains can be found: Nd-Cu rich triple junction phase (grain A), Nd-Co-Cu rich phase (Grain B), RE oxides with different oxygen contents (grain $\mathrm{C}$ and $\mathrm{D}$ ), metallic $\mathrm{Nd}$ with some content of $\mathrm{Cu}$ (grain $\mathrm{E}$ ), and $\mathrm{Zr}$-rich phase (region F). In order to provide some more quantitative information regarding to the composition of the constituent phases, four different EDS line profiles, i to iv as marked in Fig. 4 (a), are shown in Fig. 4 (b). Line profile (i) shows that $\mathrm{Nd}-\mathrm{Cu}$ rich phase has a large $\mathrm{Cu}$ content of $\sim 35$ at. \% without any oxygen enrichment. Line profile (ii) shows that the metallic $\mathrm{Nd}-\mathrm{Co}-\mathrm{Cu}$ rich phase contains $\sim 15$ and $\sim 10$ at. $\%$ of $\mathrm{Cu}$ and Co respectively. Line profile (iii) shows REOx phase and line profile (iv) shows oxide phase with a higher oxygen content. Selected areal diffraction patterns obtained from these 6 different Nd-rich grains are shown in Fig. 5. The Nd-rich phase with large $\mathrm{Cu}$ content (RE-Cu rich phase) that are mainly exist in the triple junctions of the recycled magnet, such as grain A, has the fcc structure (Fig. 5 (a)). Note that Sepehri-Amin et al. reported $\mathrm{NdCu}$ precipitates distributed in metallic Nd-rich phase in the triple junction of assintered $\mathrm{Nd}-\mathrm{Fe}-\mathrm{B}$ magnets which changes to $\mathrm{Nd}-\mathrm{Cu}$ rich triple junction phase after post-sinter annealing [16]. Sasaki et al. also reported fcc structure for $\mathrm{Nd}-\mathrm{Cu}$ rich triple junction phase of optimally annealed sintered magnets [17], which is in agreement with structure of RE-Cu rich triple junction phase observed in the recycled magnet. The selected area diffraction patterns obtained from Nd-Co-Cu rich phase (grain B marked in Fig. 4 (a)) at two different zone axis of [100] and [411] shown in Fig. 5 (b) indicates that this metallic phase also has the fcc structure. Selected area diffraction patterns obtained from rare earth oxide phase with larger oxygen concentration shown in Fig. 5 (c) obtained from grain $\mathrm{C}$ shows that this phase is hcp- $\mathrm{RE}_{2} \mathrm{O}_{3}$, $P \overline{3} m l, \mathrm{La}_{2} \mathrm{O}_{3}$ type crystal structure. The selected area diffraction patterns obtained from $\mathrm{REO}_{\mathrm{x}}$ phase, such as grain D, shows this phase is fcc- $\mathrm{REO}_{x} F m \overline{3} m, \mathrm{NaCl}$ type crystal structure. The 
selected area diffraction pattern taken from the metallic $(\mathrm{Nd}+\mathrm{Pr})$-rich phase with some minor segregation of $\mathrm{Cu}$, grain $\mathrm{E}$, show this phase is $F m \overline{3} m, \mathrm{Cu}$ type structure as shown in Fig. 5 (e). The micro-beam diffraction pattern taken from the Zr-rich phase indicates this phase is $\mathrm{P} 63 / \mathrm{mmc}$, with the Mg-type crystal structure.

Figure 6 shows more detailed analysis of the Zr-rich phase. Figure 6 (a) shows BSE-SEM and IL-SE SEM images that can be observed from the region where Zr-rich phases exist. A bright and dark contrast of lamellae can be observed in the microstructure. A high magnification STEM-HAADF image and STEM-EDS maps of $\mathrm{Fe}, \mathrm{Nd}, \mathrm{Cu}, \mathrm{Zr}$, and $\mathrm{Co}$ obtained from such a region is shown in Fig. 6 (b). Figure 6 (c) shows EDS line profile obtained from the selected region marked in the STEM-HAADF map in Fig. 6 (b), showing the (Nd+Pr)-rich phase with a lamella structure containing 17 at.\% of $\mathrm{Cu}$ and around 5 at. \% of Co while $\mathrm{Zr}$-rich region is mainly $\mathrm{Zr}$ with amount of 70 at. \%.

Figure 7 (a) and (b) show serial sectioning of SEM-BSE and constructed 3D tomography of Nd-rich phases from recycled magnet (see the supplementary file for 3D tomographic movie). 3D tomography was constructed out of 172 SEM-BSE images with $40 \mathrm{~nm}$ depth step. The rareearth oxide phases are shown with bright contrast while the metallic rare-earth phases are shown with a reddish yellow color. This result shows that Nd-rich intergranular phases are interconnected through the grain boundaries in the recycled magnet.

\subsection{Composition of the grain boundary phase}

Figure 8 (a) show BSE-SEM images obtained from the recycled magnets. The contrast of the image is enhanced for a better visualization of the grain boundary phase and the interfaces. Thin white contrast through the grain boundaries of the recycled magnet indicates the formation 
of the Nd-rich grain boundary phase in the recycled magnet. A weak bright gray contrast can be also observed in the outer region of $\mathrm{Nd}_{2} \mathrm{Fe}_{14} \mathrm{~B}$ grains of the recycled magnet. Figure 8 (b) shows STEM-EDS maps of Dy and Nd obtained from the recycled magnet. It can be seen that Dy is not distributed uniformly in the $\mathrm{Nd}_{2} \mathrm{Fe}_{14} \mathrm{~B}$ grain; there is a Dy-rich shell in the outer region of $\mathrm{Nd}_{2} \mathrm{Fe}_{14} \mathrm{~B}$ grains. This can found more clearly in the composition profile of $\mathrm{Fe}, \mathrm{Nd}+\mathrm{Pr}, \mathrm{Co}, \mathrm{Cu}$, and Dy, shown in Fig. 8 (c) obtained from the rectangular region shown in Fig. 8 (b). The Dy content in the shell region is around 0.8 at. $\%$ while that inside of the grains reduces to 0.2 at. $\%$ in the recycled magnet.

Figure 9 (a) to (c) show high resolution STEM-HAADF images obtained from three typical grain boundary phases with different tilting angle with respect to the c-axis of $\mathrm{Nd}_{2} \mathrm{Fe}_{14} \mathrm{~B}$ grains in the recycled magnet. The grain boundary phase perpendicular to the c-axis of a $\mathrm{Nd}_{2} \mathrm{Fe}_{14} \mathrm{~B}$ grain shows crystalline structure with a thickness of $\sim 3.5 \mathrm{~nm}$ (Fig. 9 (a)). However, the grain boundary phase located parallel to the easy axis of $\mathrm{Nd}_{2} \mathrm{Fe}_{14} \mathrm{~B}$ grains show an amorphous structure as shown in Fig. 9 (c). STEM-EDS composition profiles of the grain boundary phases are shown in Fig. 9 (d) to (f). It can be seen that the crystalline grain boundary phase located perpendicular to the easy axis of $\mathrm{Nd}_{2} \mathrm{Fe}_{14} \mathrm{~B}$ grain contains 66.5 at. $\%$ of $\mathrm{Nd}+\mathrm{Pr}, 23.8$ at. $\%$ of $\mathrm{Fe}$, and 5.9 at.\% Cu. Fig. 9 (e) shows STEM-EDS line profile obtained from the grain boundary phase with 33 degree tilting angle from c-axis of $\mathrm{Nd}_{2} \mathrm{Fe}_{14} \mathrm{~B}$ grain (Fig. 9 (b)) indicating that the grain boundary phase contain 45 at. $\%$ of $\mathrm{Nd}+\mathrm{Pr}, 43$ at. $\%$ of $\mathrm{Fe}$, and 6.5 at. $\%$ segregation of $\mathrm{Cu}$. STEM-EDS line profile obtained from the grain boundary phase located almost parallel to the easy axis of $\mathrm{Nd}_{2} \mathrm{Fe}_{14} \mathrm{~B}$ grain is shown in Fig. 9 (f) indicating that the grain boundary phase contain 27.8 at. $\%$ of $\mathrm{Nd}+\mathrm{Pr}$ and 62.4 at. $\%$ of $\mathrm{Fe}$ with 5.8 at. \% segregation of $\mathrm{Cu}$ in the grain boundary phase. 


\section{Discussion}

It was shown that the addition of $\mathrm{Nd}_{6} \mathrm{Dy}_{21} \mathrm{Co}_{19} \mathrm{Cu}_{2.5} \mathrm{Fe}$ alloy powder to the recycled $\mathrm{Nd}-$ Fe-B powders during the powder processing is an effective way to develop full density recycled $\mathrm{Nd}-\mathrm{Fe}-\mathrm{B}$ magnet. SEM observations showed that addition of $\mathrm{Nd}_{6} \mathrm{Dy}_{21} \mathrm{Co}_{19} \mathrm{Cu}_{2.5} \mathrm{Fe}$ alloy powder provide sufficient amount of metallic $\mathrm{Nd}$ for the liquid sintering process, resulting in the development of full density recycled Nd-Fe-B magnets. In addition, a uniform Nd-rich phase was found at the grain boundaries of the recycled magnet, which is attributed to the recovery or improvement of the coercivity. The magnetic properties of the recycled magnet $\left(\mu_{0} H_{\mathrm{c}}=2.36 \mathrm{~T}\right.$ and $\left.\mu_{0} M_{\mathrm{r}}=1.29 \mathrm{~T}\right)$ are higher than those of the commercial NMX-43SH grade sintered magnet $\left(\mu_{0} H_{\mathrm{c}}=2.21 \mathrm{~T}\right.$ and $\left.\mu_{0} M_{r}=1.25 \mathrm{~T}\right)$ that contains about $4.45 \mathrm{wt} \%$ Dy. The overall Dy and oxygen contents in the recycled magnet $(\mathrm{Dy}=3.42 \mathrm{wt} \%$ and $\mathrm{O}=0.13 \mathrm{wt} \%)$ are lower than those of the commercial NMX-43SH grade sintered magnet $(\mathrm{Dy}=4.45 \mathrm{wt} \%$ and $\mathrm{O}=0.42 \mathrm{wt} \%$ ). This indicates that selective addition of $\mathrm{Nd}$ and Dy alloy powders as the grain boundary modifier results in the development of the recycled magnets with even superior magnetic properties than that of original Nd-Fe-B sintered magnets.

One question is how the individual elements of the GBM${ }^{\mathrm{TM}}$ are distributed in the microstructure of the recycled Nd-Fe-B magnet. Microstructure analysis of the recycled magnet showed that substantial amount of the additives forms isolated Nd-rich phases containing metallic $\mathrm{Nd}+\mathrm{Pr}, \mathrm{Nd}-\mathrm{Cu}$ rich, and $\mathrm{Nd}-\mathrm{Co}-\mathrm{Cu}$ rich phases combined with rare earth oxides. Some part of Dy was found to diffuse into $\mathrm{Nd}_{2} \mathrm{Fe}_{14} \mathrm{~B}$ grains making a thick Dy-rich shell and Dy-lean core structure. STEM-EDS results showed that Dy content in the shell and core region of the $\mathrm{Nd}_{2} \mathrm{Fe}_{14} \mathrm{~B}$ grains in the recycled magnet was 0.8 and 0.2 at. \%, respectively. This type of 
core/shell structure is commonly observed in the Nd-Fe-B sintered magnets processed from multiple alloy powders $[18,19]$.

Composition profiles obtained from the STEM-EDS analysis of the grain boundary phases of the recycled magnet showed that the one located perpendicular to the c-axis of $\mathrm{Nd}_{2} \mathrm{Fe}_{14} \mathrm{~B}$ grains have a crystalline structure with a higher $\mathrm{Nd}+\mathrm{Pr}$ content than that of the amorphous grain boundary phase located parallel to c-axis. In fact, this irregular distribution of Nd-rich phase in the grain boundary phase was first reported in the hot-deformed Nd-Fe-B magnets [20-22]. More recently, such a feature was also reported in the commercial Nd-Fe-B sintered magnets [17]. The thickness of the grain boundary phase perpendicular to the c-axis is $\sim 3.7-4.3 \mathrm{~nm}$ and that parallel to the c-axis is $\sim 2.4 \mathrm{~nm}$ in the recycled magnet. These are thicker than the exchange length of $\mathrm{Nd}_{2} \mathrm{Fe}_{14} \mathrm{~B}$ phase, $1.97 \mathrm{~nm}$, which is defined as $l_{e x}=\sqrt{\frac{A}{\mu_{0} M_{S}^{2}}}$, where $A$ and $\mu_{0} M_{s}$ are exchange stiffness and saturation magnetization of $\mathrm{Nd}_{2} \mathrm{Fe}_{14} \mathrm{~B}$ phase, $8 \times 10^{-}$ $12 \mathrm{~J} / \mathrm{m}$ and $1.61 \mathrm{~T}$ [23]. The existence of only 23.8 at. $\% \mathrm{Fe}$ in the grain boundary phase perpendicular to c-axis suggests that the grains are exchange decoupled parallel to c-axis direction while they might be still exchange coupled perpendicular to c-axis direction since $\sim 62.4$ at.\% Fe exist at the grain boundaries parallel to c-axis of the $\mathrm{Nd}_{2} \mathrm{Fe}_{14} \mathrm{~B}$ grains. Based on these microstructure analysis, it can be concluded that formation of thick grain boundary phase, large $\mathrm{Nd}$ content at the grain boundary phase, good interconnection of Nd-rich phases, and the formation of the Dy-rich shell explains the high coercivity in the recycled magnet. Further modification of the microstructure, such as composition modification of the grain boundaries parallel to c-axis will lead to further enhancement of the coercivity. 


\section{Summary}

Full-density recycled Nd-Fe-B sintered magnets were produced by the addition of a new grain boundary phase $\left(\mathrm{GBM}^{\mathrm{TM}}\right)$ modifier, $\mathrm{Nd}_{6} \mathrm{Dy}_{21} \mathrm{Co}_{19} \mathrm{Cu}_{2.5} \mathrm{Fe}$ alloy powders, to the powders produced from Nd-Fe-B waste magnets. The recycled magnet showed $\mu_{0} H_{\mathrm{c}}$ of $2.36 \mathrm{~T}$ and $\mu_{0} M_{\mathrm{r}}$ of $1.29 \mathrm{~T}$ with the net Dy content of $3.42 \mathrm{wt} \%$ showed superior coercivity and thermal stability to those of the commercial NMX-43SH grade sintered magnet with Dy content of 4.45 wt $\%$. Detailed microstructure characterizations revealed two main reasons for the substantial enhancement of coercivity in the recycled magnet; the formation of distinct grain boundary phase and enrichment of $\sim 0.8$ at. \% Dy in the shell of $\mathrm{Nd}_{2} \mathrm{Fe}_{14} \mathrm{~B}$ grains. The former led to the reduction of exchange coupling among $\mathrm{Nd}_{2} \mathrm{Fe}_{14} \mathrm{~B}$ grains in the c-axis direction and the latter enhanced the local anisotropy of the main phase, which explain the high coercivity of the recycled magnet with 5.0 wt $\%$ addition of the GBM ${ }^{\mathrm{TM}}$.

\section{Acknowledgment}

This work was in part supported by CREST, JST.

All materials and magnetic alloys described in this work were exclusively designed, invented, and created by Urban Mining Company prior to this collaboration and without input from any other party. NIMS conducted all analyses described in this work in collaboration with Urban Mining. 


\section{References}

[1] K. Hono, H. Sepehri-Amin, Strategy for high-coercivity Nd-Fe-B magnets, Scripta Mater. 67 (2012) 530-536.

[2] M. Sagawa, Development and prospect of the Nd-Fe-B sintered magnets, Proc. of REPM'10, Bled, Slovenia, p. 183-186.

[3] M. Itoh, M. Masuda, S. Suzuki, K. I. Machida, Recycling of rare-earth sintered magnets as isotropic bonded magnets by melt-spinning, J. Alloys Compd. 374 (2004) 393-296.

[4] E. A. Perigo, S. C. da Silva, R. V. Martin, H. Takiishi, F. J. G. Landgraf, Properties of hydrogenation-disproportionation-desorption-recombination $\mathrm{NdFeB}$ powders prepared from recycled sintered magnets, J. Appl. Phys. 111 (2012) 07A725_1-07A725_3.

[5] R.S. Sheridan, R. Sillitoe, M. Zakotnik, I. R. Harris, A. J. Williams, Anisotropic powder from sintered NdFeB magnets by the HDDR processing route, J. Magn. Magn. Mater. 324 (2012) 6367.

[6] O. Gutfleish, K. Guth, T. G. Woodcock, L. Schultz, Recycling used Nd-Fe-B sintered magnets via a hydrogen-based route to produce anisotropic resin bonded magnets, Advanced Energy Materials, 3 (2013) 151-155.

[7] T. Kawasaki, M. Itoh, K. I. Machida, Reproduction of Nd-Fe-B sintered magnet scraps using a binary alloy blending technique, Materials Transactions 44 (2003) 1682-1685.

[8] M. Zakotnik, I. R. Harris, A. J. Williams, Possible methods of recycling NdFeB-type sintered magnets using the HD/degassing process, J. Alloys Compd. 450 (2008) 525-531.

[9] M. Zakotnik, I.R. Harris, A. J. Williams, Multiple recycling of NdFeB-type sintered magnets, J. Alloys Compd. 469 (2009) 314-321. 
[10] T. S. Jang, D. H. Lee, A. S. Kim, S. Namgung, H. W. Kwon, D. H. Hwang, Recovery of high coercivity of the powders obtained by crushing Nd-Fe-B sintered magnet scraps, Phys. Stat. Sol. (a) 201 (2004) 1794-1797.

[11] H.W. Kwon, I.C. Jeong, A.S. Kim, D.H. Kim, S. Namkung, T.S. Jang, D.H. Lee, Restoration of coercivity in crushed Nd-Fe-B magnetic powder, J. Mag. Mag. Mater. 304 (2006) e219-e221.

[12] X. T. Li, M. Yue, W. Q. Liu, X. L. Li, X. F. Yi, X. L. Huang, D. T. Zhang, Large batch recycling of waste $\mathrm{Nd}-\mathrm{Fe}-\mathrm{B}$ magnets to manufacture sintered magnets with improved magnetic properties, J. Alloy Comp. 649 (2015) 656-660.

[13] M. Zakotnik, C. O. Tudor, Commercial-scale recycling of NdFeB-type magnets with grain boundary modification yields products with 'designer properties' that exceed those of starting material', Waste Management. 44 (2015) 48-54.

[14] T.T. Sasaki, T. Ohkubo, Y. Une, H. Kubo, M. Sagawa, K. Hono, Effect of carbon on the coercivity and microstructure in fine-grained Nd-Fe-B sintered magnet, Acta Mater. 84 (2015) $506-514$

[15] W. F. Li, T. Ohkubo, K. Hono, M. Sagawa, The origin of coercivity decrease in fine grained Nd-Fe-B sintered magnets, J. Magn. Magn. Mater. 321 (2009) 1100-1105.

[16] H. Sepehri-Amin, T. Ohkubo, T. Shima, K. Hono, Grain boundary and interface chemistry of an Nd-Fe-B-based sintered magnet, Acta Mater. 60 (2012) 819-830.

[17] T. T. Sasaki, T. Ohkubo, K. Hono, Structure and chemical compositions of the grain ` boundary phase in Nd-FE-B sintered magnets, Acta Mater. 115 (2016) 269 - 277.

[18] M. Honshima, K. Ohashi, High-energy NdFeB magnets and their applications, J. Mater. Eng. Perform. 3 (1994) 218-22. 
[19] W. F. Li, H. Sepehri-Amin, T. Ohkubo, N. Hase, K. Hono, Distribution of Dy in highcoercivity (Nd,Dy)-Fe-B sintered magnets, Acta Mater. 59 (2011) 3061-3069.

[20] J. Liu, H. Sepehri-Amin, T. Ohkubo, K. Hioki, A. Hattori, K. Hono, Microstructure evolution of hot-deformed Nd-Fe-B anisotropic magnets, J. Appl. Phys. 115 (2014) 17A744_117A744_3.

[21] H. Sepehri-Amin, T. Ohkubo, S. Nagashima, M. Yano, T. Shoji, A. Kato, T. Schrefl, K. Hono, High-coercivity ultrafine-grained anisotropic Nd-Fe-B magnets processed by hotdeformation and the Nd-Cu grain boundary diffusion process, Acta Mater. 61 (2013) 6622-6634. [22] H. Sepehri-Amin, J. Liu, T. Ohkubo, K. Hioki, A. Hattori, K. Hono, Enhancement of coercivity of hot-deformed Nd-Fe-B anisotropic magnet by low-temperature grain boundary diffusion of $\mathrm{Nd}_{60} \mathrm{Dy}_{20} \mathrm{Cu}_{20}$ eutectic alloy, Scripta Mater. 69 (2013) 647-650.

[23] J. M. D. Coey, Magnetism and Magnetic Materials, Cambridge University Press, Cambridge, 2009, pp. 265-266 
Figure 1: (a) Demagnetization curves of starting materials and recycled magnets and (b) coercivity versus temperature of the starting material and recycled magnet.

Figure 2: (a) and (b) Back scattered electron (BSE) SEM and (c) and (d) in-lens secondary electron (IL-SE) SEM images obtained from starting waste magnet and recycled magnet, respectively.

Figure 3: Back scattered electron (BSE) SEM and EDS maps of $\mathrm{Nd}, \mathrm{Co}, \mathrm{Cu}, \mathrm{O}, \mathrm{Dy}$, and $\mathrm{Zr}$ obtained from (a) starting waste magnet and (b) recycled magnet.

Figure 4: (a) STEM-EDS maps of $\mathrm{Nd}, \mathrm{Fe}, \mathrm{Cu}, \mathrm{Zr}$, Dy, Co, and $\mathrm{O}$ obtained from the recycled magnet; and (b) Composition profiles obtained from STEM-EDS line scans i to iv, as marked in (a).

Figure 5: Selected area diffraction patterns obtained from 6 different rare earth (RE)-rich grains marked in Fig. 4a: (a) $\mathrm{RE}-\mathrm{Cu}$ rich phase, (b) $\mathrm{RE}-\mathrm{Co}-\mathrm{Cu}$ rich phase, (c) $\mathrm{RE}_{2} \mathrm{O}_{3}$, (d) $\mathrm{REO}_{\mathrm{x}}$, (e) metallic Nd, and (f) Zr-rich phase.

Figure 6: (a) SEM-BSE and IL images showing lamella contrast from Nd-rich grains obtained from the recycled magnet. (b) STEM-HAADF image and STEM-EDS maps of Fe, $\mathrm{Nd}$, $\mathrm{Cu}, \mathrm{Zr}$, and Co obtained from the same area shown in (a). (c) EDS-line profile obtained from selected line marked in (b) showing that the lamella structure contains Zr-rich and $(\mathrm{Nd}+\mathrm{Pr})-\mathrm{Co}-\mathrm{Cu}$ phases.

Figure 7: (a) 3D series of BSE SEM images and (b) 3D tomography of Nd-rich phases for the recycled magnets. 
Figure 8: (a) BSE SEM images obtained from the recycled magnet, (b) STEM-EDS maps of Dy and $\mathrm{Nd}$ obtained from the recycled magnet. (c) The composition profile of $\mathrm{Fe}, \mathrm{Nd}+\mathrm{Pr}$, $\mathrm{Co}, \mathrm{Cu}$, and Dy obtained from selected line shown in Dy map.

Figure 9: (a) - (c) High resolution STEM-HAADF images obtained from grain boundaries of the recycled magnet with different tilting angle with respect to the easy axis of $\mathrm{Nd}_{2} \mathrm{Fe}_{14} \mathrm{~B}$ grains. (d) - (f) STEM-EDS composition profiles of constituent elements obtained across the Nd-rich grain boundary phases. 
a)

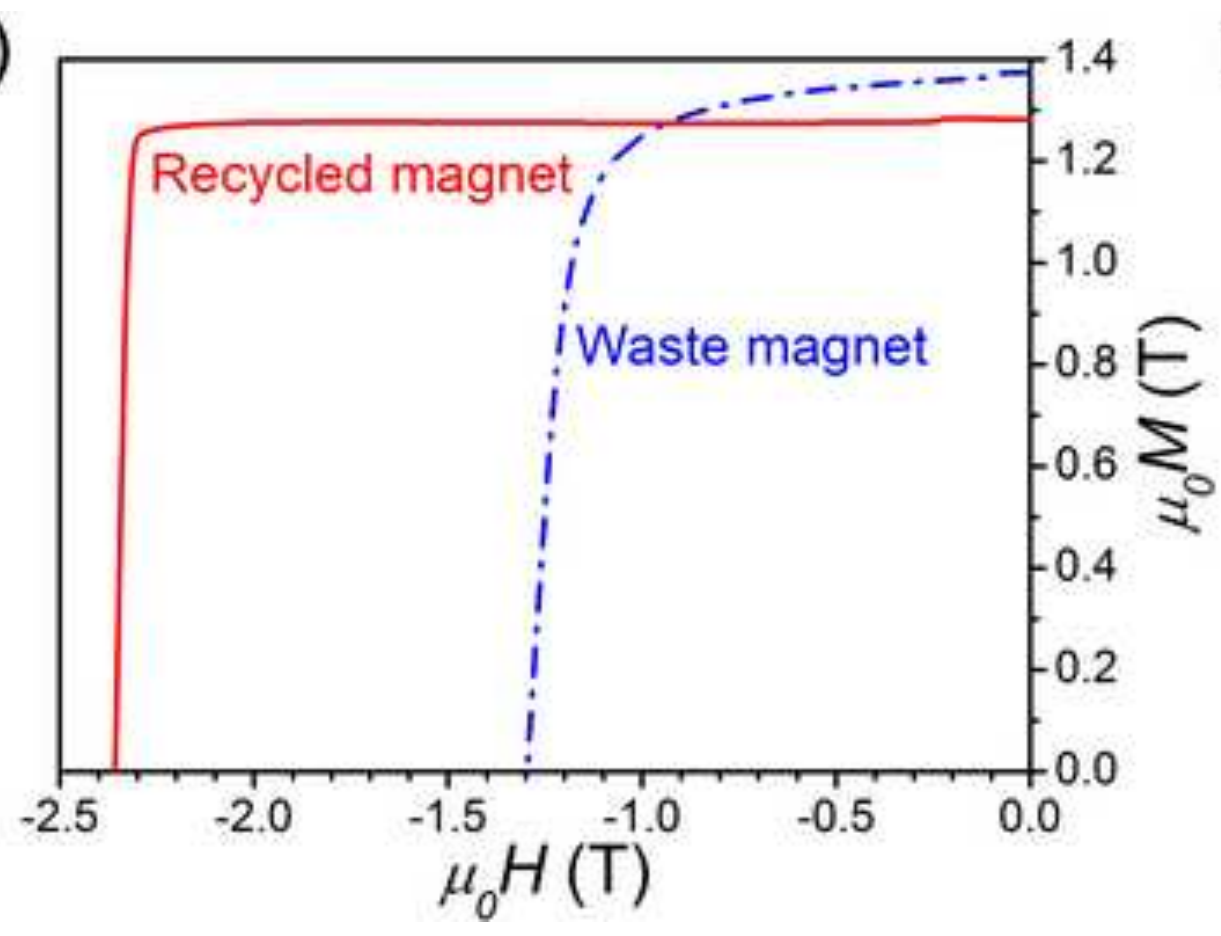

b)

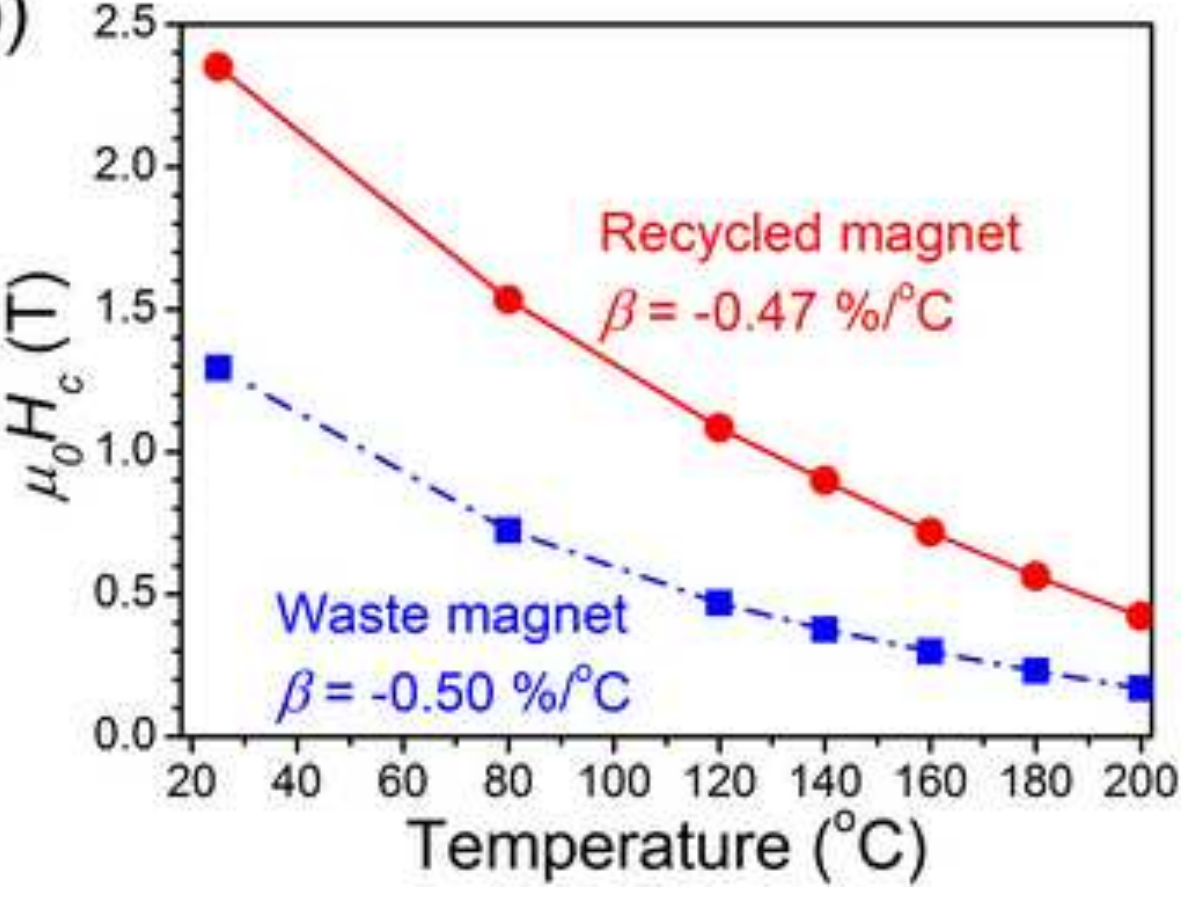


Waste magnet

a) BSE,

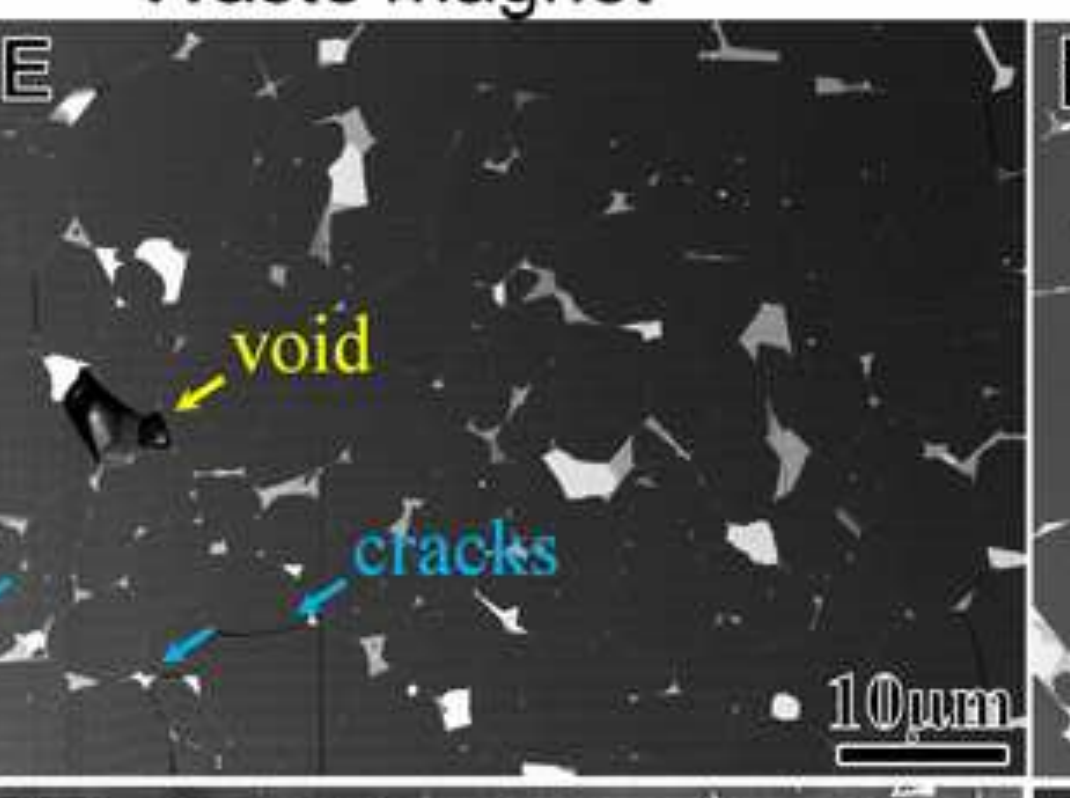

Recycled magnet 
a) SEM-EDS maps obtained from waste magnet

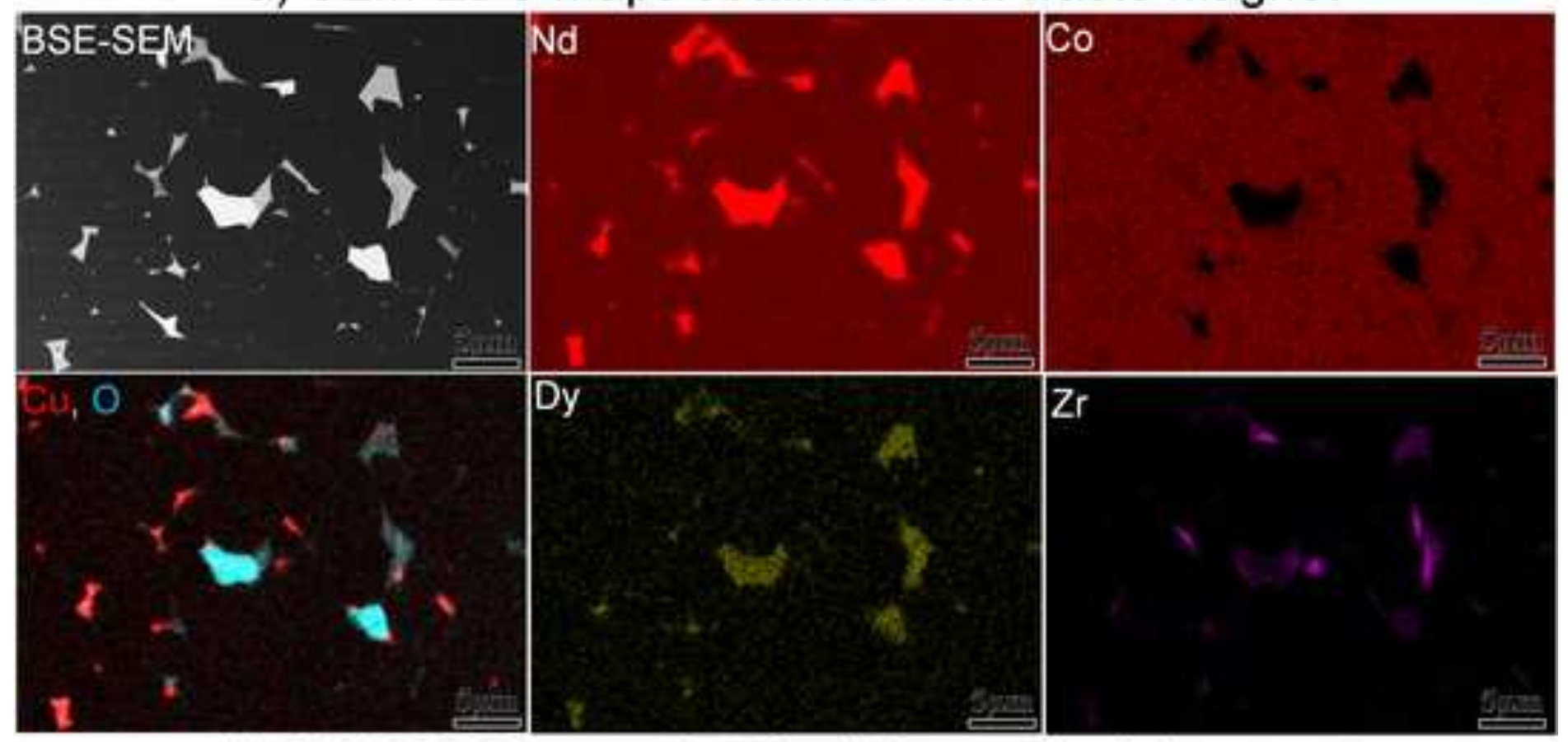

b) SEM-EDS maps obtained from recycled magnet

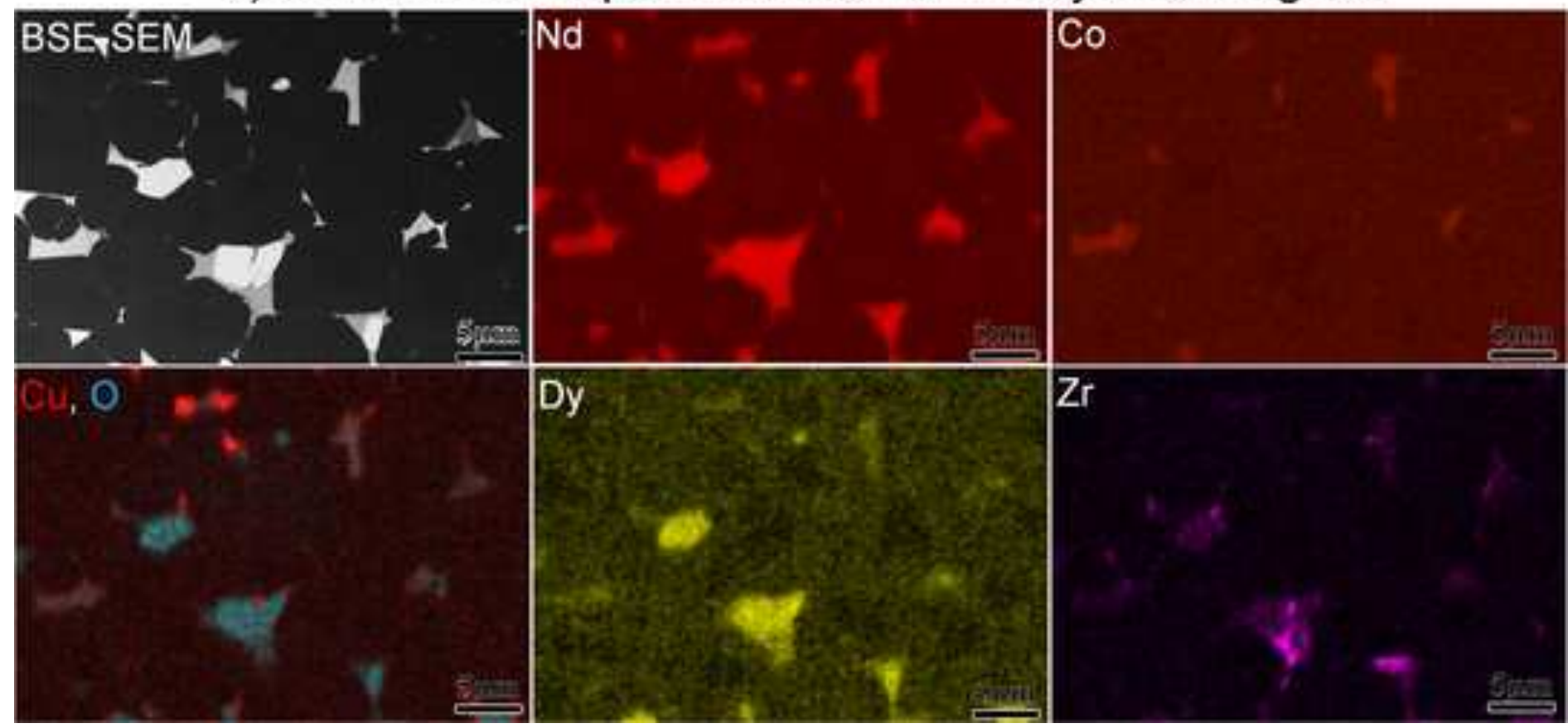


a) Nel. FPe

$\stackrel{\circ}{\mathrm{E}}$

oD

b)
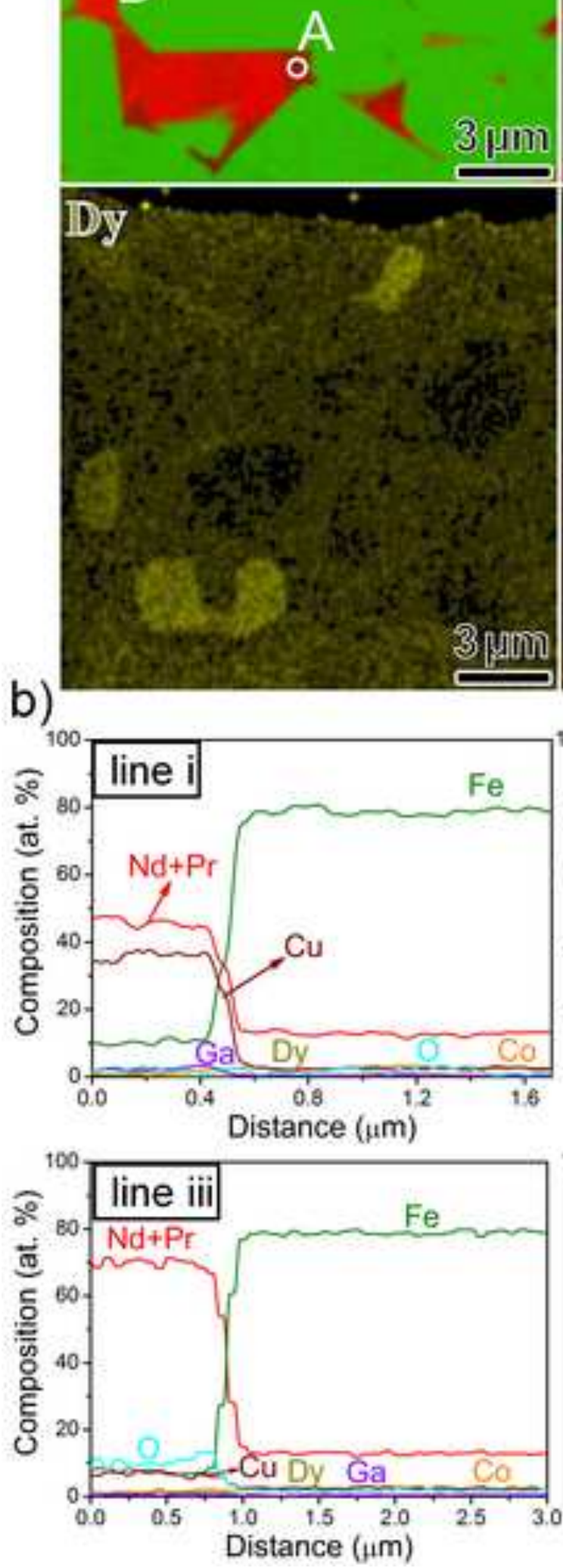

$\mathbb{C}$ un, Zn

iा a d

Fa

зимп

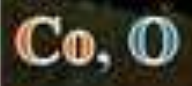

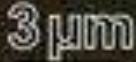

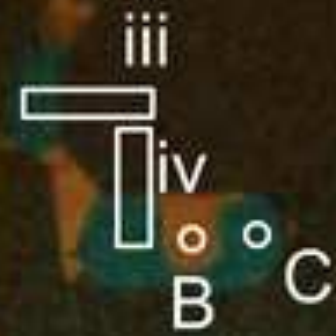

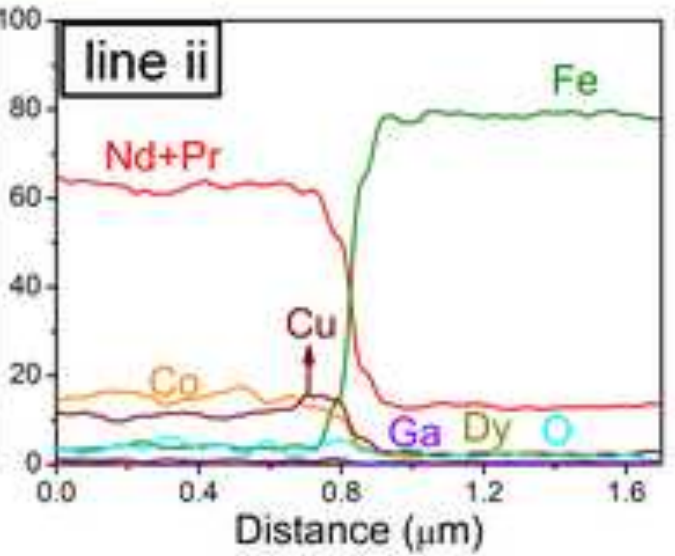

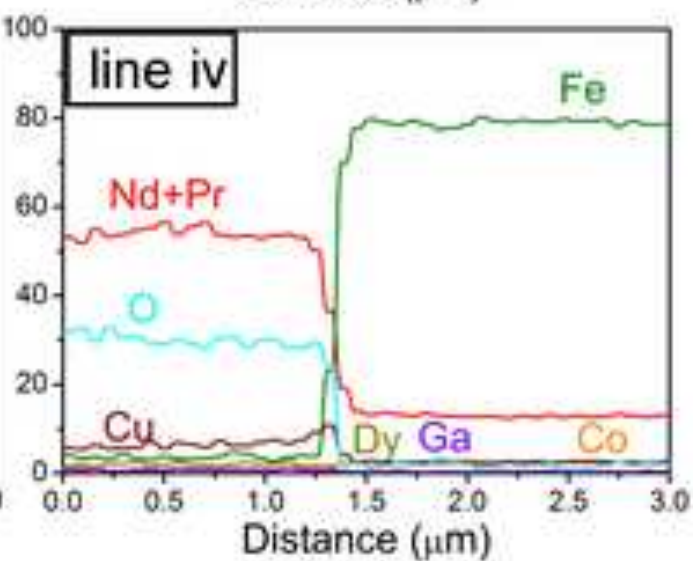


a) RE-Cu rich phase

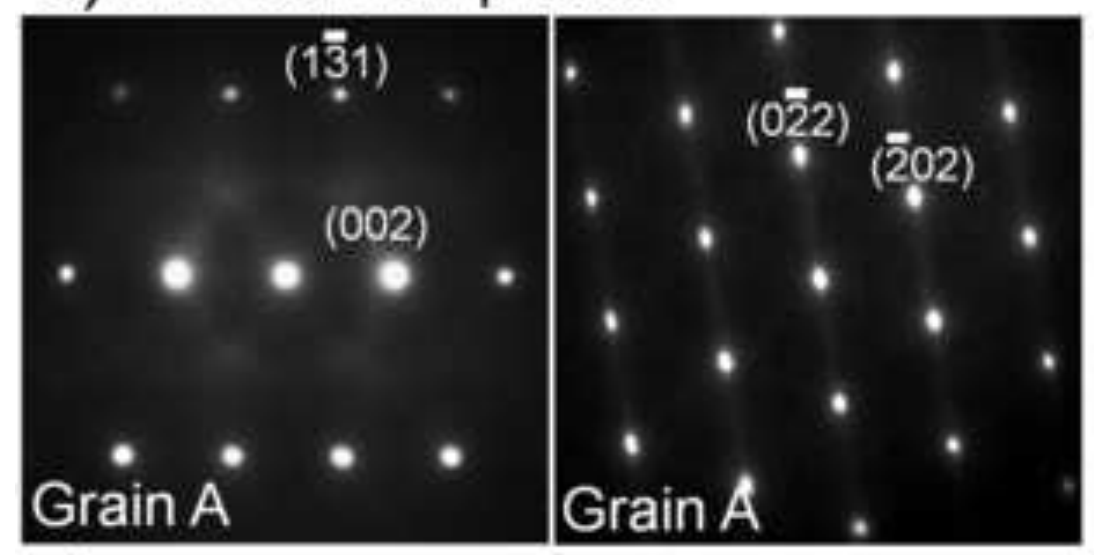

C) $\mathrm{RE}_{2} \mathrm{O}_{3}$

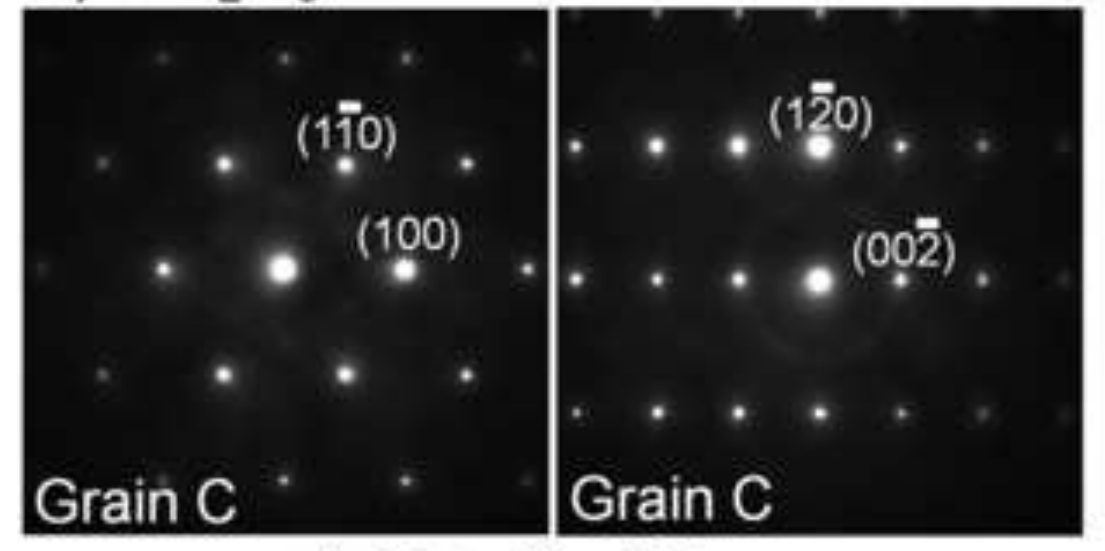

e) Metallic Nd

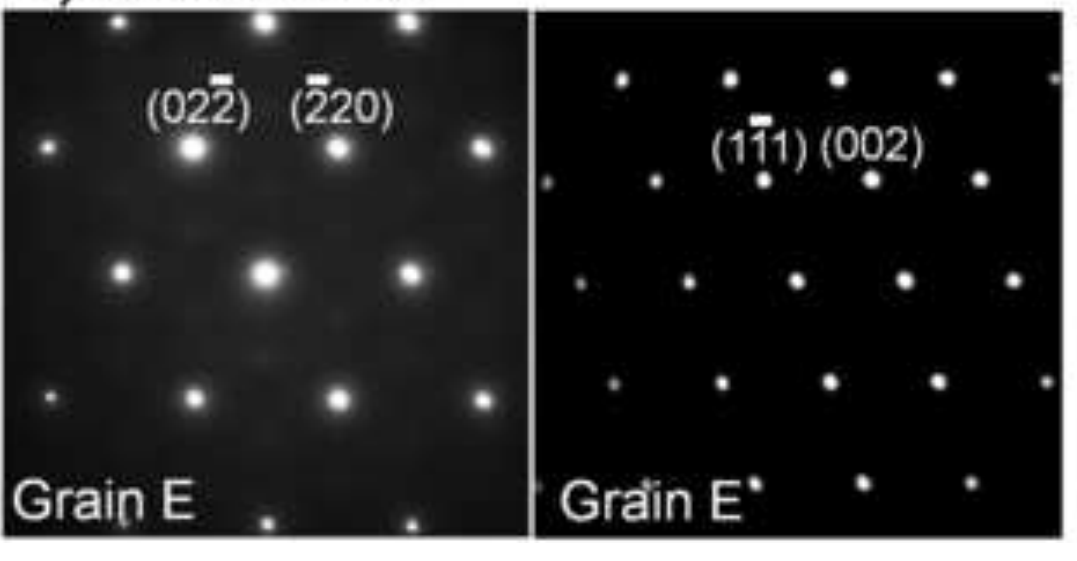

b) RE-Co-Cu rich phase

Grain B

d) $\mathrm{REO}_{x}$ phase

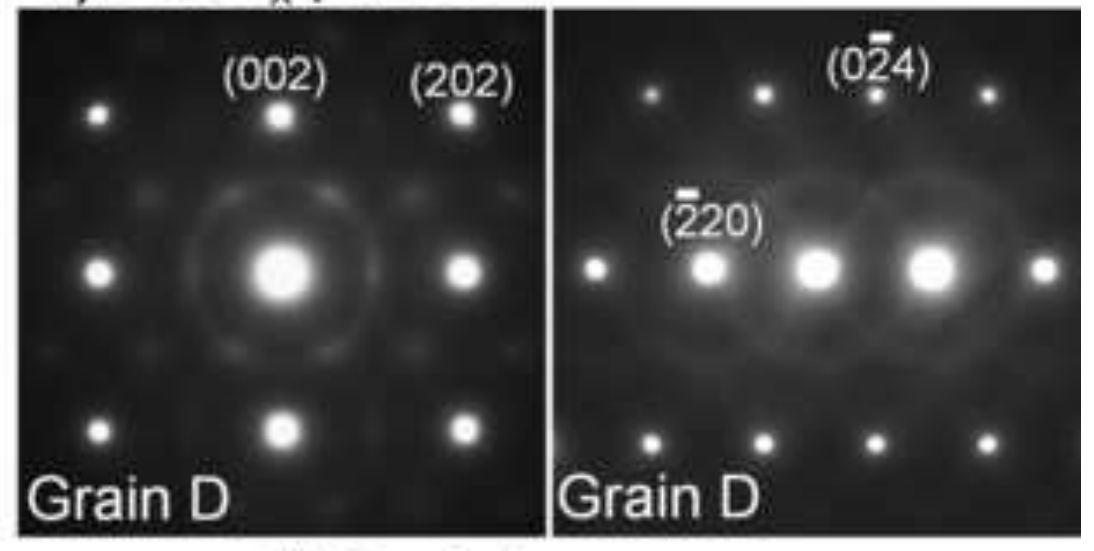

f) Zr-rich

Grain F

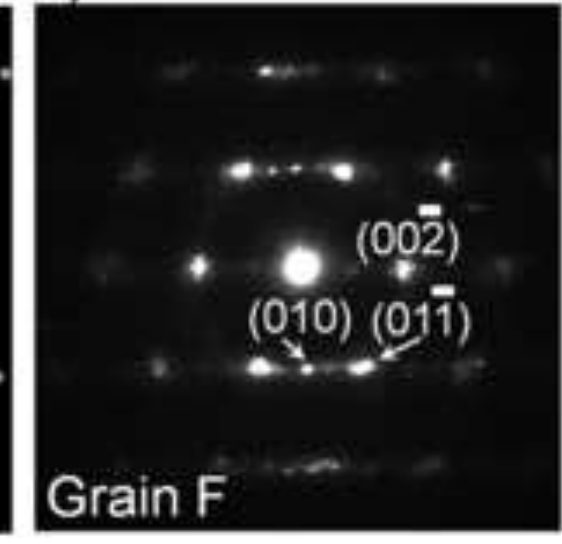



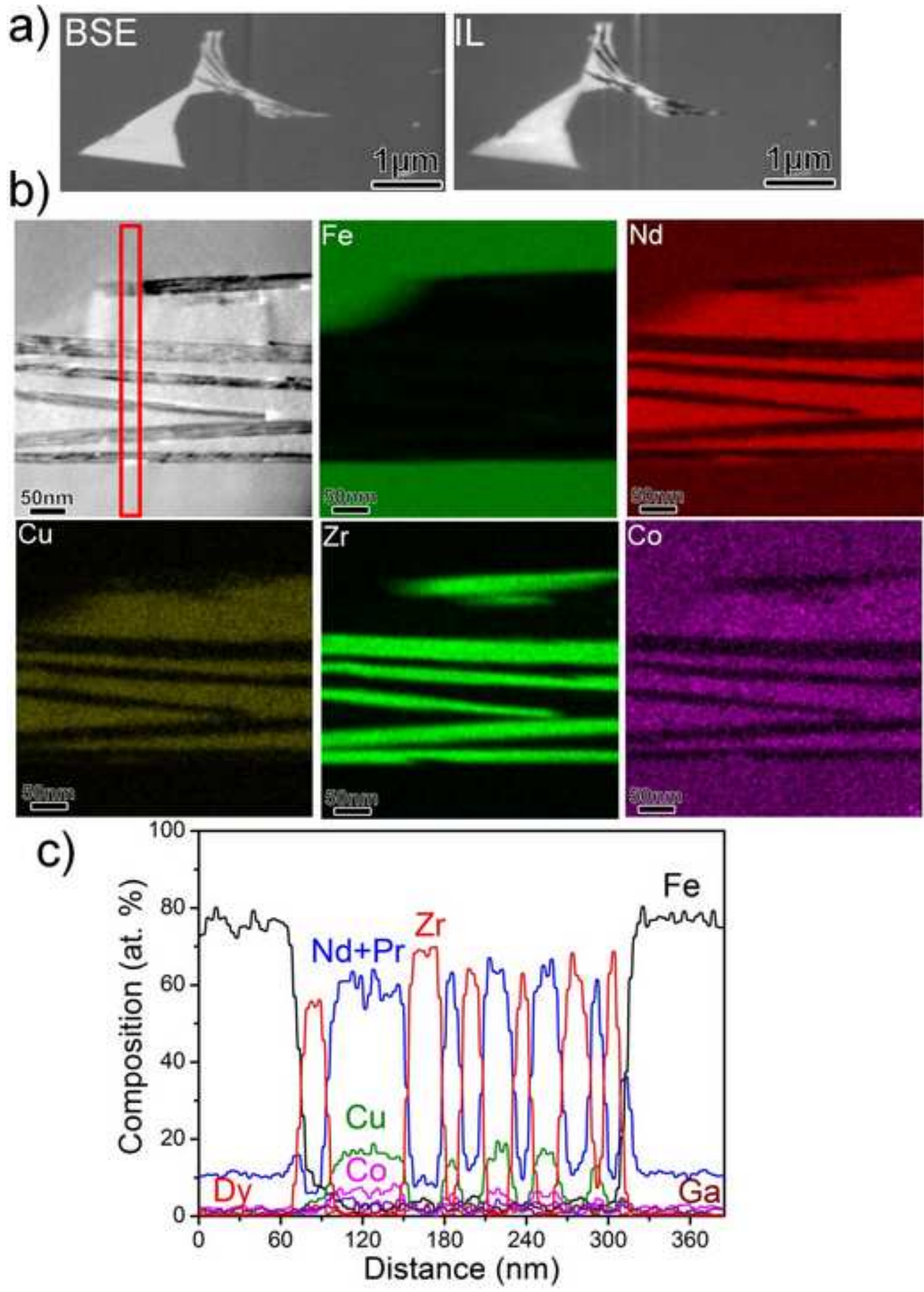
a) Recycled magnet

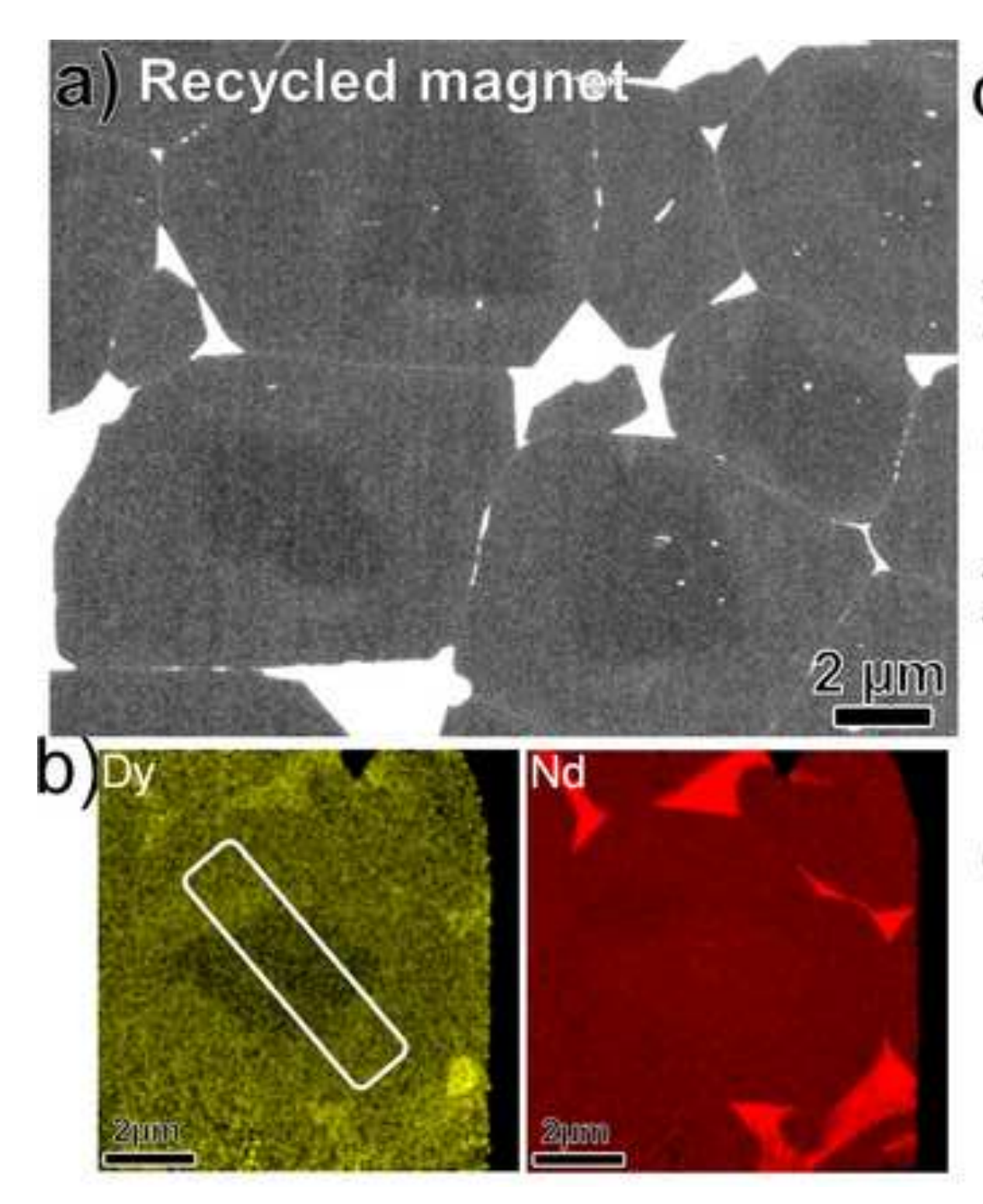

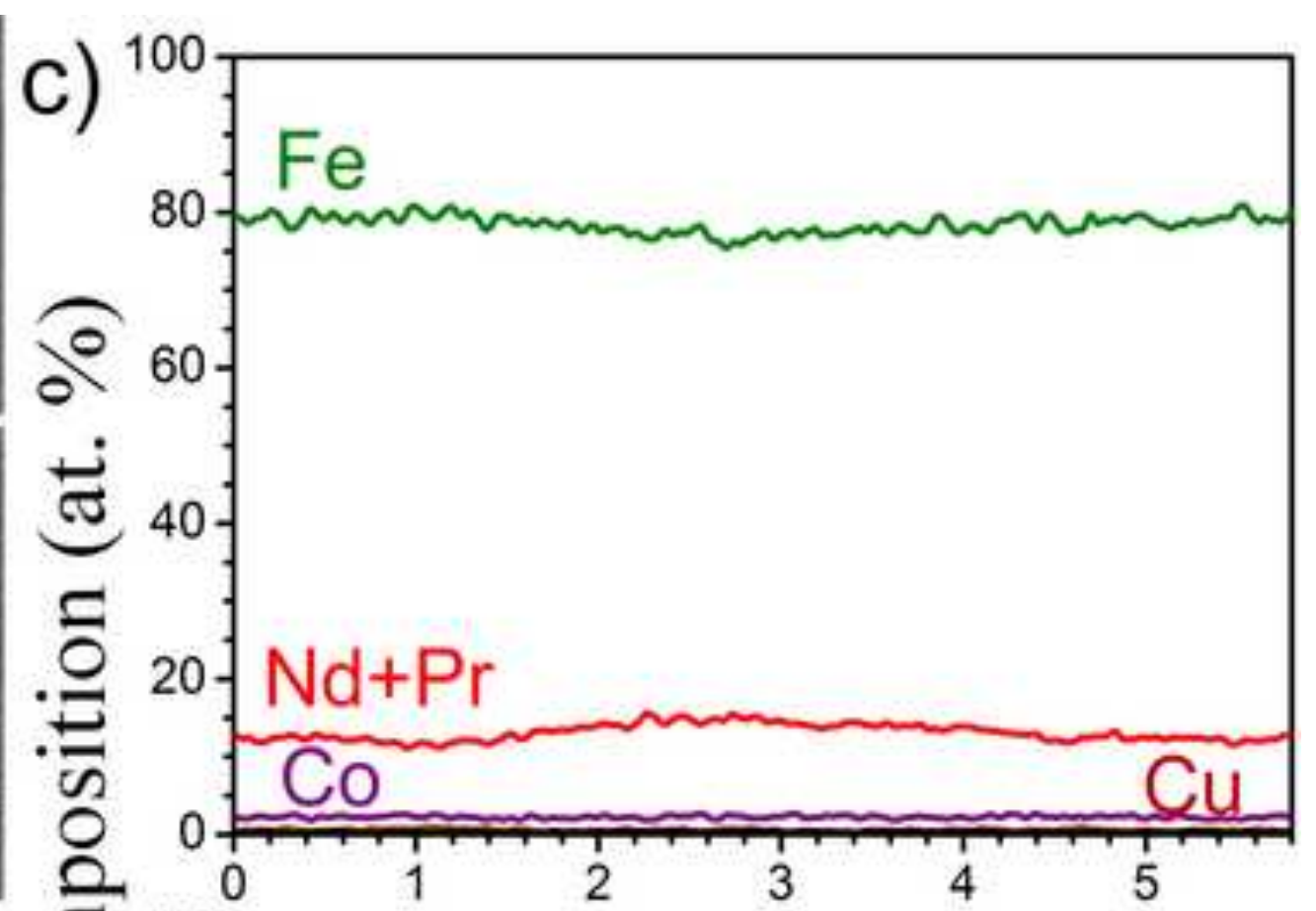

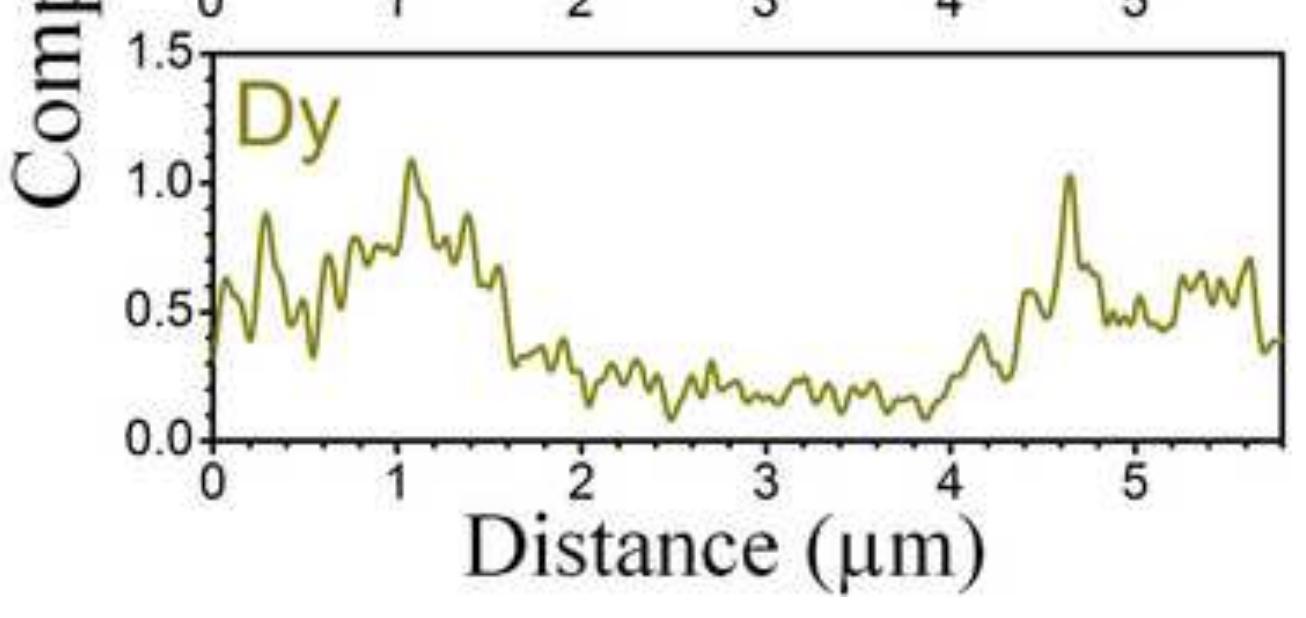



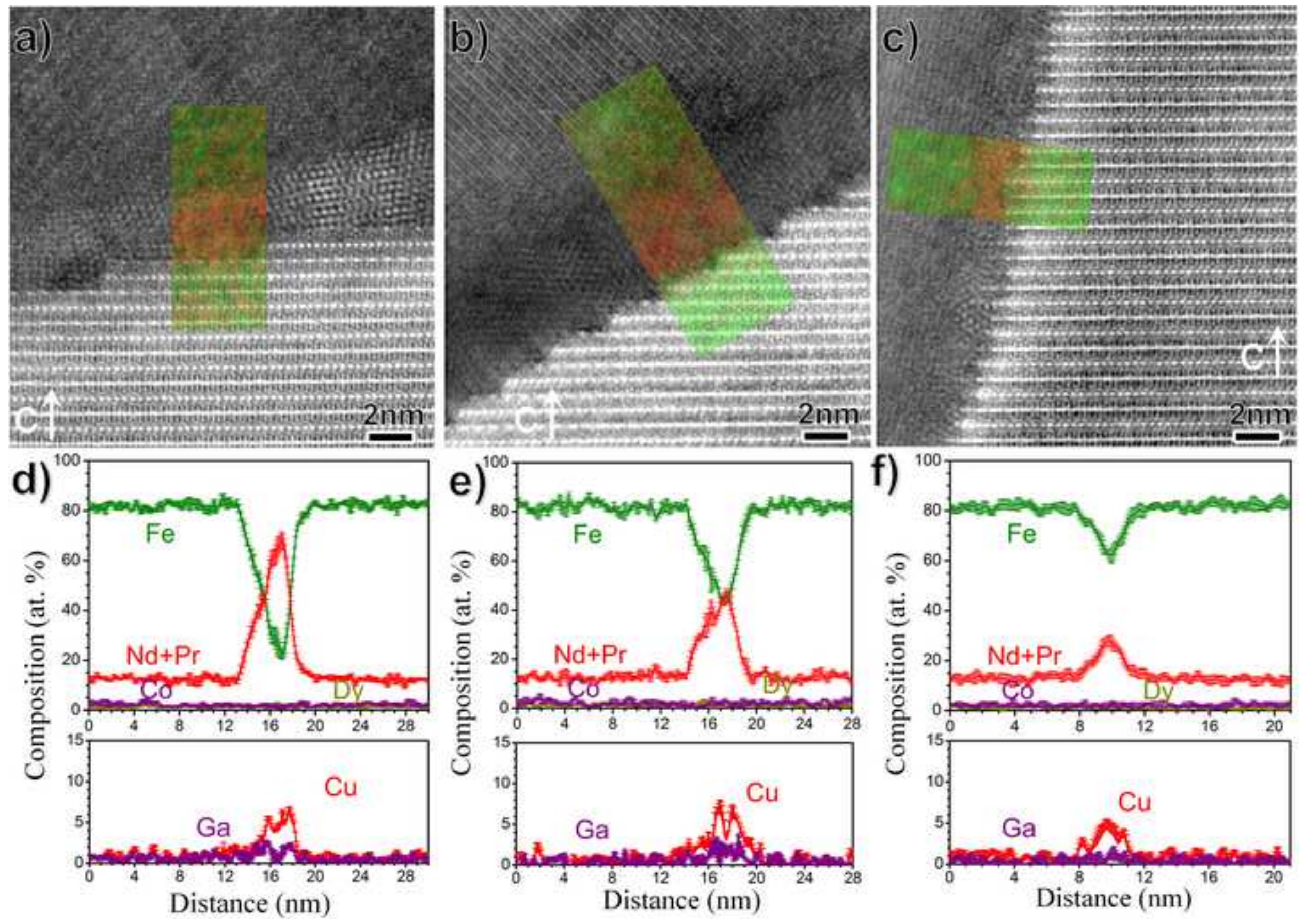